\title{
Unearthed: The Other Side of Group Cohesiveness
}

\author{
Lata Dyaram and T. J. Kamalanabhan* \\ Department of Humanities \& Social Sciences, Indian Institute of Technology, Madras, \\ Chennai 600 036, Tamilnadu, India \\ E-mail: ldyaram@yahoo.com, *tjkv@hotmail.com
}

KEYWORDS Work groups; cohesiveness; performance; group norms; task interdependence

\begin{abstract}
One of the most consistently studied constructs in group dynamics research is Cohesiveness. It is a fact, that there is a tendency to see the effects of group cohesiveness as being largely positive. The periodic review of cohesiveness-performance relation had been positive. However, not much attention has been devoted to the fact that group cohesiveness can be detrimental to the group performance and other group outcomes. There are only few studies, which focuses on this aspect of cohesiveness. The objective of this paper is to examine and throw light upon other aspects of cohesiveness, which requires much needed attention. The present paper in contrast to majority of cohesiveness studies suggest a simple relation between cohesiveness - performance, seeks out to discuss the plausibility of some of the very few studies, which tried to empirically find out the other side of cohesiveness. The paper supporting these studies, suggests that the relationship between cohesiveness and performance is not that simple and may not necessarily result in better performance. The paper also highlights the need for future empirical research, which could test this relationship.
\end{abstract}

\section{INTRODUCTION}

This paper attempts to briefly examine the definitions of the construct Group cohesiveness and the factors, which were emphasized in defining this construct. Later it highlights on the gradual development of the distinction between task cohesion and social cohesion as a result of plethora of definitions on group cohesiveness. In later part of the paper, the relationship between performance-productivity and the other side of cohesiveness are discussed.

Group cohesiveness has been one of the extensively studied constructs in group literature (Bettenhausen, 1992). Several researchers have attempted to define cohesiveness. Cohesion is defined as " a dynamic process reflected in the tendency for a group to stick together and remain united in the pursuit of instrumental objectives and/or the satisfaction of member affective needs" (Carron et al., 1987).

Cohesiveness has been the central feature in the studies related to groups and group dynamics. It has been found to be one of the critical influencing factors over workgroup performance. Cohesiveness could be understood as the degree to which members of a group are attached to one another and have the desire to remain a part of the group. Group cohesiveness remained one of the most interesting and elusive construct for researchers in group dynamics may be because of the accepted belief that cohesiveness would contribute to satisfaction of affiliation need of the group members (Zaccaro, 1986) and moderate the detrimental effects of environmental constraints on organizational behavior (Evans, 1991) and thereby lead to considerable better performance (Langfred et al., 1998). Several reviews described group cohesiveness as the resultant forces, which are acting, on the members to stay in a group and much of research in cohesiveness literature accepted this description although it has been criticized as vague. Group cohesiveness has been considered as an important construct in wide variety of groups viz. sports teams, work teams, exercise groups, therapy groups, task groups etc. and group processes in terms of communication patterns, influencing behavior, behavior changes. However, defining this construct of group cohesion and measuring it, remains a debatable and controversial question since 1950s (Mudrack et al., 1989). Hence, there is no clear operational definition widely accepted per se of this construct and a clear strategy to measure it. Some researchers have adopted unidimensional model to measure this construct while most of the other recent studies have emphasized on multidimensional models and measures of group cohesion.

In his classical description, Mudrack (1989) describes a cohesive group as " one that "sticks together'- one whose members are bonded to one another and the group as a whole". Earlier researchers have considered cohesiveness in 
terms of "attraction to group" and equated cohesion with other constructs such as 'groupspirit', 'bonds of interpersonal attraction', 'affective bonds', 'sense of belongingness', 'sticking together', 'sense of we-ness' etc (Mudrack, 1989). Evans and Dion (1991), thought cohesiveness to imply " an individuals desire to remain a member in the group". Others have observed that "attraction" may be seen as a cause of cohesiveness rather than as an effect of membership i.e. attraction is an antecedent rather than a consequent condition for cohesiveness. Hence they defined cohesion in phenomenological terms, as perceived belongingness (feeling a part of the group) and perceived morale (feelings of morale, enthusiasm to be a part of a group). Still others in their examination of factors related to small group cohesiveness defined cohesion as "the average of the individual members' attraction to the group". They found a strong correlation between cohesiveness and empathy, self disclosure, acceptance and trust. They concluded that cohesion is positively related to these factors, also " an equally good (or perhaps better) case can be made that an increase in these factors will lead to an increase in cohesion". Thus much of cohesiveness literature has focused primarily on 'attraction' factor to measure cohesiveness. However, such focus on 'attraction' factor met with considerable criticism. One such criticism is about too much of focus being given to 'individuals in groups, rather than 'group' in group cohesiveness and thus losing out on entire clear picture of group cohesiveness.

More contemporary views on cohesiveness as a multidimensional concept, considers attraction as just one of the factor. Attraction to group goals has been perceived gradually as, just one of the reasons to get attracted to the group. It is not necessary that members in the group like each other and it is possible that the group goals may be strong enough to hold the group together to stick and act as one even in the absence of mutual attraction. Moreover, group members may be cohesive though disagree on group goals (Mudrack et al., 1989). Several other researchers have focused on distinguishing between task cohesion and social cohesion.

\section{GROUP COHESION AND GROUP} PERFORMANCE

Difficulties in defining and measuring the construct 'group cohesiveness' did not deter researchers from investigating this construct and its effect on various other factors in group work. Much of the research since 1950s and 60s have attempted to associate group cohesiveness with productivity. Studies on cohesion-performance relation have found that in highly cohesive groups, productivity tends to be higher, and they tend to participate readily, defend the group norms, express hostility, feel a sense of security, influence others and be influenced and stay with the group. Evans \& Dion (1991) did a meta analysis of various studies on group cohesion and performance. In all the studies they found that cohesion was related to performance or productivity. They noted this relationship as “ moderately strong and in a positive direction $(\mathrm{r}=$ +.419)". Some researchers found a positive correlation between cohesiveness in small technology firms and their financial performance. Group cohesiveness was also observed to be an important "curative factor in therapy" and has been noted that it has a therapeutic value for promoting personality change. Significant positive correlation was found between selfreported measures of personality change and cohesion scores. Review of research of cohesion in sport teams and exercise groups has found team success, collective efficacy and group communication to be positively related to performance (Bettenhausen et al., 1991). Similar relationship was found in other studies in groups with high goal acceptance and high levels of drive.

Studies, which examined effects of cohesiveness on employee job performance, all found a positive relation between cohesiveness and productivity (Schacter et al., 1951). Gradually cohesiveness was recognized as one of the best possible predictor of group performance.

Several comprehensive meta analysis studies were carried out with the purpose of examining a clear relationship between cohesion-performance, as well as exploring several variables that could affect this relationship (Evan and Dion, 1991; Mullen and Copper, 1994). Unfortunately, many of these studies are not free from key conceptual and methodological issues and there persists the confusion regarding the cohesionperformance relationship. For instance, shortcomings in terms of level of analysis in these studies raise many methodological issues. Most of the time, cohesion has been operationalized at 
individual level but the findings have been generalized to the group level. The unit of analysis is always been 'individual' in group rather than it being 'group' itself (Gully et al., 1995). Now, to what extent such operationalization of cohesion at individual level or group level will be more related to performance is debatable but certainly gives more insight and captures a broad spectrum of group variables to assess cohesionperformance relationship. The rationale behind this is that performance is often studied in terms of entire group i.e. group effectiveness, group performance etc, hence it is reasonable to study such cohesion-performance relationship where the unit of analysis being the group itself rather than individuals.

Another important aspect, which needs attention, is, the kind of moderator variables that affect this cohesion-performance relationship. There are several studies, which have attempted to probe for these factors, be it environmental factors, organizational factors or group/ individual factors. However, empirical studies in this aspect, emphasizing on antecedent variables that typically affect cohesion-performance relationship are rare. In general, group size, group goals, norms etc have received much attention in these studies.

There has been a fundamental need to highlight those variables, which affect this relationship significantly. In a study conducted by (Gully et al., 1995) task interdependence was a major factor found to be affecting this relationship significantly. According to these researchers, cohesion-performance relationship is determined by the nature of the task. The tasks, that require much of interaction, communication, interdependence, coordination, mutual monitoring among members are strongly related to determine this relationship than the tasks, which require minimal presence of these factors (Zaccaro et al., 1986 ).

Although many recent studies distinguished between task cohesion and social cohesion and also have found them to be important determinants of performance, which one of these is the better predictor of performance, definitely needs to be studied further. In this regard, Mullen and Copper (1994) supports task cohesion as the better and stronger determinant.

According to Gully et al. (1995), there are only few empirical studies, which have examined how these two types of cohesion affect group processes and performance, particularly for different type of tasks.

\section{THE OTHER SIDE OF GROUP COHESIVENESS}

Though considerable research has addressed time and again the cohesion-performance relationship, the 1972 review of studies on cohesiveness and performance found this relationship to be inconsistent: "In about a third of the studies reviewed more cohesive groups were more productive whereas in another third, more cohesive groups were less productive" (Stogdill, 1972; Langfred, 1998). After considerable literature survey, one would say that performance outcomes for cohesive groups remained a total contrast from either very productive and efficient or to very unproductive and inefficient. Several studies did find that average productivity of cohesive groups was quite close to that of non-cohesive groups. These findings suggest that more important moderating variables exist which affects this relationship to greater extent (Langfred, 1998). These findings are consistent with the observation that cohesiveness did not have a positive relationship with performance until combined with task focused or task oriented group norms (Schachter et al.,1951).

These inconsistencies as mentioned earlier could be attributed to conceptual and methodological issues in such studies and their operationalization of the constructs. Moreover, there are few experimental findings to support the presence of moderator variables affecting this relationship of cohesion-performance. However, the possibility of presence of such moderators were studied in different research setups through different methods. Schachter et al. (1951) found in their studies that cohesiveness-productivity relationship was being moderated by the extent to which the group considered the task important. Such presence of moderators and their effect on cohesion-performance relation has also been acknowledged by Tziner et al. (1982) who suggested that cohesive groups may not be always more productive. The importance of moderator variables is still considered paramount in the work of Langfred (1998), Gully et al. (1995).

It is very much surprising that inspite of research efforts which shows the evidence of moderator variables affecting this cohesionperformance relationship and how it could be detrimental to the group performance, still the 
snapshot impression is to look at the effects of this particular factor in largely positive terms. It is not very clear why such bias is still persisting. May be one could attribute such positive bias to the much supportive research backup since decades especially in varied types of groups. However, the need to study this factor empirically in specific work teams or groups in organizational setup has been felt time and again.

No doubt there is ample evidence to show the positive effects of this factor. For instance, satisfaction with coworkers was found to be relatively high in cohesive groups ( $\mathrm{O}^{\prime}$ Reilly and Caldwell, 1985). Members in cohesive groups protect themselves from stress and maintain their health through their cohesion and groupness. This factor also found to reduce turnover and absenteeism and contribute to effective group performance; and performance in turn can lead to cohesion (Gully et al., 1995). It was found to give them a feeling of security and identity and find themselves stronger in such cohesive groups.

Nevertheless, little is known about not so beneficial aspect of cohesiveness. This needs much attention especially in today's organization where the buzzword is "teams" and one might reasonably expect the more cohesive the team, the better it will be in terms of productivity and performance. It is time to look at the other side of cohesiveness and throw light upon those factors, which moderate the much-hyped positive relationship between cohesiveness and performance. This need to look at the moderator variables involved in this relationship becomes especially underpinning if one reviews the consistent findings by studies which have shown that such relationship depends on the performance related norms established by the group. If such norms are high, the group will be productive than a less cohesive group. But if cohesiveness alone is high and performance norms are low, productivity is predicted to be low (Gully et al., 1995).

Langfred (1998) in his study found that group task norms moderate the relationship between group cohesiveness and group effectiveness. He found groups with high cohesiveness and task norms were only more effective than other groups and that the combination of high cohesiveness and non-task norms were found to be associated with poor performance. His study captured much of complexity involved in group cohesiveness and performance with varied kind of group tasks and more importantly, it takes in to account organizational set up.

Usually the cohesiveness factor is viewed from social aspect i.e. from interpersonal attraction rather than task cohesion per se although there are researches which went on to distinguish between these two kinds of cohesion. According to Langfred (1998) cohesiveness is not productive if task behavior is considered less important compared to social aspect of cohesion. This may be so because too much of emphasis on interpersonal relations could be detrimental to the task at hand. This sounds something similar to the age-old debate on, which leadership style is better- whether it is task oriented leader or relationship/interpersonal oriented leader. Now one needs to realize that relying on any one thing certainly could be detrimental. As members in the group could be frustrated with over emphasis on just task accomplishments and similarly too much of socializing could be less productive or perhaps counterproductive. Emphasis on task cohesion may lead to poor member relations, which in turn would get in the way of successful completion of group assignments. Many researchers went on to suggest that interpersonal cohesion and task cohesion would affect performance in different ways. Usually it is expected that higher task cohesion would lead to better group performance and higher social cohesion may be negatively linked to performance. There is reason to believe in the former relationship, as with higher task cohesion there is generally higher level of commitment, effort and willingness among the group members for task accomplishment. Now the latter relationship is of a little complex nature. Before this demarcation of task and social cohesion it was found in general, social/interpersonal group cohesion to be positively linked to group performance (Lott and Lott, 1965). Few studies argued that interpersonal attraction will not necessarily lead to better performance as group members priorities and concerns vary from task oriented dimension to people oriented dimension. Moreover, interaction patterns not pertaining to group tasks may be detrimental to group performance. Unless group goals are related to group task, mere group cohesion will not be beneficial for group performance (Mullen et al., 1994). Bartkus (1995) in their study found that highly cohesive groups were more productive than less cohesive groups, when leader exhibited strong task initiation behavior (Seung and James, 
2002). Similarly, Zaccaro and Lowe (1986) found that interpersonal cohesion was positively related to interaction frequency $(\mathrm{r}=.30, \mathrm{p}<.01)$, which was in turn negatively related to group performance $(\mathrm{r}=-.37, \mathrm{p}<.01)$ (Gully et al., 1995). These findings indicate the negative relationship between interpersonal cohesion and performance. Hence it requires perhaps a balanced proportion of interpersonal and task cohesion to lead to better performance. Much of group dynamics literature has focused on how group cohesion would affect group performance. Researchers like Mullen and Copper (1994), found the other way round relationship. For instance, groups who were informed about their performance being better rated themselves as more cohesive than groups who were told that their performance was poor, though that information about performance was completely unrelated to their actual performance.

Another important area where group cohesion was viewed critically is in the 'Group Think' literature (Janis, 1972). Highly cohesive groups enforce group norms far more effectively than less cohesive groups and pressure to conform to these norms is dramatically high in highly cohesive groups. Such cohesive groups are more tilted towards so called 'interpersonal' cohesion. They try to please one another, avoid confrontation and deviant thoughts. Though the members may disagree privately, just to belong to the group and take pride in their association with the group, they tend to conform. And usually this is at the cost of task productivity. Deviant members get isolated from the entire group. The group uses self-defensive and self-protective strategies and does not tolerate nor encourage any challenges or criticisms from the group members nor from outsiders. Failures are perceived as enmity from others and thus end up in bad and poor quality decisions. Janis (1972) rightly describes this process of bad decision making in highly cohesive groups as 'Group Think'.

"The effect of group cohesiveness on the quality of decision making is a core element of Janis (1972) theory of group think" (Mullen and Brian, 1994). He defines groupthink as 'a mode of thinking that people engage in when they are deeply involved in a cohesive group when the members' strivings for unanimity override their motivation to realistically appraise alternative courses of action'. He went on to describe many antecedent conditions to this group think process and considered cohesiveness as the main important factor contributing to group think. It was often been noted that the antecedent conditions on group think most prominently mentioned by Janis was high group cohesiveness. Though cohesiveness was considered as the important factor for the group think process in the group and thereby poor decision-making, Janis himself and others did formulate that cohesiveness is certainly a necessary condition for group think but not a sufficient condition. Other antecedent variables such as directive leadership would also affect this group think process. But certainly cohesiveness factor in combination with these other antecedents would help to increase or decrease the decision quality in the groups.

Mullen et al. (1994) found in their study that when other antecedent conditions specified by Janis are set up to promote group think, high cohesiveness impairs decision making, whereas when other antecedent conditions are set up to thwart group think, high cohesiveness enhances decision making. In large groups he found high cohesiveness actually impairing decision quality, which Janis rightly formulated that such poor decisions result from concerted effort among group members to match their behavior to some behavioral standard of unanimity, consensus and mutual support. According to self-attention theory, it is a self regulated social impairment process where groups' standard of excellence in performance focuses more on consensus than on high quality decisions. "The more cohesive the group, the easier it might be for the individual to become 'lost in the crowd' and thereby cease to engage in self regulated attempts to match to behavioral standards" (Mullen, 1994). Another interesting thing, which is formulated, is whether this impairment in decision quality could not only be active concurrence seeking behavior, which Janis termed as, group think, it could also be relatively inactive failure to engage in tasks in the first place. Similarly, the more the group is cohesive, the more is the pressure to conform to group norms and suffer from group think (Langfred et al.,1998). Thus highly cohesive groups are more vulnerable to problems such as group think and block their creative thinking for problem solving approaches due to their high cohesion and conformity behavior. Though researchers have argued and reviewed Janis's work very few studies have been empirically tested and subjected to direct examination. 
Though some researchers have attempted to develop a scale to measure group think, difficulty in testing this construct has led to fewer empirical research.

\section{CONCLUSIONS AND FUTURE RESEARCH}

It is clear that group performance is affected certainly by a combination of group cohesiveness and other factors like norms, interdependence of the task etc rather than cohesiveness factor alone. Given the research support, it is very important to realize and create awareness, contradictory to traditional views, particularly in organizational setups and especially among top management and decision making bodies who tend to employ work groups and work teams expecting high results, about the detrimental effects of cohesiveness factor. Similarly it is important to be aware of such effects by considering the cohesiveness factor alone, without such mediator and moderating variables viz: task oriented norms, group size, nature of the task etc. These detrimental effects would be more pronounced by combining cohesiveness with non task oriented norms, tasks involving low levels of communication, interaction etc.

More empirical research is needed to show to what extent cohesiveness factor alone leads to better/poor performance.

Future empirical research is needed to investigate this uncertain relationship between cohesion-performance in wide variety of contexts and setups. This would enable us to capture the true relationship, that would certainly help to provide new and more promising insights into this elusive construct Group Cohesiveness in group dynamics literature.

\section{REFERENCES}

Bartkus, R. Kenneth. 1995. "Group Cohesiveness and Performance in the Salesforce: The Impact of Active and Passive Mechanisms of Direction." Journal of Professional Services Marketing, 13: 145-54.

Bettenhausen, K. and J.K. Murnigham. 1985. "The emergence of norms in competitive decision making groups." Administrative Science Quarterly, 30(3): 350-372

Bettenhausen K.L 1991. "Five years of group research: What we have learned and what needs to be addressed." Journal of Management, 17: 345-381.

Brawley L.R., A.V. Carron and W.N. Widmeyer. 1987. "Assessing the cohesion of teams: Validity of the Group Environment Questionnaire." Journal of Sport Psychology, 9: 275-294.

Brawley L.R., A.V. Carron and W.N. Widmeyer. 1988. Exploring the Relationship between cohesion and group resistance to disruption." Journal of Sport \& Exercise Psychology, 10: 199-213.
Carron, A.V. and S.R. Bray. 2002. "Team cohesion and team success in sport." Journal of Sport Sciences, 20: $119-226$.

Evans C.R. and K.L. Dion. 1991. "Group Cohesion and performance: A Meta Analysis." Small Group Research, 22(7): 175-186.

Evans, C.R. and K.L. Dion. 1992. "On cohesiveness. Reply to keyton and other critics of the construct." Small Group Research, 23(2): 242-250.

Gully S.M., D.J Devine and D.J Whitney. 1995. "A meta analysis of cohesiveness and performance: Effects of level of analysis and task interdependence." Small Group Research, 26(4): 497-520.

Janis, I.L. 1972. Victims of Groupthink: A Psychological Study of Foreign Policy Decisions and Fiascoes. ( $2^{\text {nd }}$ edition). Boston: Houghton Mifflin.

Keyton I. 1992. "Comment on Evans and Dion: Still more on group cohesion." Small group Research, 23(2): 237-241.

Lang Fred, Claus W. 1998. "Is cohesiveness a double edged sword?" Small Group Research, 29: 124-139.

Leana, C.R. 1985. "A partial test of Janis Group think model: Effects of group cohesiveness and leader behavior on defective decision making." Journal of Management, 11: 5-7.

Lott A.D. and B.E Lott. 1965. "Group cohesiveness as interpersonal attraction: A review of relationships with antecedent and consequent variables." Psychological Bulletin, 64, 259-309.

Mudrack, P.E. 1989. "Group cohesiveness and productivity: A closer look." Human Relations, 42(9): 771-785.

Mullen, Brian, Anthony and Tara. 1994. "Group cohesiveness and quality of decision-making. Small Group Research, 25(2): 189-205.

Mullen, B. and C. Copper. 1994. "The relationship between group cohesiveness and performance: An integration." Psychological Bulletin, 115(2): 210227

O'Reilly, C.A. and D.F Caldwell. 1985. "The impact of normative social influence and cohesiveness on task perceptions and attitudes: A social information processing approach." Journal of Occupational Psychology, 58: 193-206.

Schachter, S., N. Ellertson, D. Mc Bride and D. Gregory. 1951. "An experimental study of cohesiveness and productivity." Human Relations, 4(4): 299-338.

Seung, Y.K. and V.S. James 2002. "Influence of contextual performance and leader Member Exchange (LMX) relationships on group cohesion and group performance: A preliminary model." Paper submitted to ORB/OT track of the Midwest Academy of Management Conference.

Stogdill, R.M. 1972. "Group productivity, drive and cohesiveness." Organizational Behavior and Human Performance, 8: 26-43.

Tziner, A. and Y. Vardi 1982. "Effects of command style and cohesiveness on the performance effectiveness of self selected tank crews." Journal of Applied Psychology, 67(6): 769-775.

Wech, Barbara A. 1998. "Does work group cohesiveness affect individuals' performance and organizational commitment: A cross level examination." Small Group Research, 29: 472-491.

Zaccaro, S.J. and C.A Lowe. 1986. "Cohesiveness and performance on an additive task: Evidence for multidimensionality." Journal of Social Psychology, 128(4): 547-558. 